\title{
Monetary Policy Transmission Mechanism in Nigeria: A Comparative
} Analysis

\author{
Ngozi Frances Obafemi ${ }^{1} \&$ Eugene Okoi Ifere ${ }^{1}$ \\ ${ }^{1}$ Department of Economics University of Calabar, Calabar, Nigeria \\ Correspondence: Eugene Okoi Ifere, Department of Economics, University of Calabar, Calabar, Nigeria. Tel: \\ 234-805-405-7717.
}

Received: November 17, 2015

Accepted: December 10, $2015 \quad$ Online Published: December 16, 2015

doi:10.5430/rwe.v6n4p93

URL: http://dx.doi.org/10.5430/rwe.v6n4p93

\begin{abstract}
Empirical evidence has shown that the result of the exact channel of monetary policy transmission in Nigeria is mixed. This paper compared the Factor-augmented vector-auto regression (FAVAR) framework which exploits large data set of 53 with the traditional VAR model that estimates 6 variables to ascertain the exact channel of transmission. Findings from the two models conclude that although both methods generate qualitatively related results, but the FAVAR model is a superior alternative over VAR on grounds that monetary policy shocks are better identified using the FAVAR model. Also the FAVAR model does not exhibit the prize puzzle problem found in the VAR but allows for the computation of impulse responses of a large number of variables. Results from both models show that interest rate and credit channels are dominant and strongest channels of monetary policy transmission in Nigeria. Exchange rate and money channels were not significant and pronounced.
\end{abstract}

Keywords: monetary policy, transmission mechanism, prize puzzle, FAVAR, VAR

\section{Introduction}

Identifying the exact and effective channel of monetary policy transmission is of great necessity for good policy-making. However, this has remained an unsettled monetary policy issue in contemporary times especially in developing economies like Nigeria. Also in the list of contemporary challenging monetary policy issues are the "problem of lag (impact),price stability, environment in which monetary policy is operating, effectiveness of standard monetary policy measures in steering inflation, "secular stagnation" meaning a persistent state of economic depression" (Praet, 2014; Obafemi \& Ifere 2015). Others are the challenge of undeveloped financial sector, autonomy in operation of the Central Bank and free borrowing by federal government from the Central Bank of Nigeria (CBN) at below market-clearing interest rates. However, despite the measures taken by $\mathrm{CBN}$ in recent times by adopting different monetary policy regimes, monetary policy has continued to remain uncertain. Suggesting that inadequate knowledge of transmission mechanism can affect lofty objectives of monetary policy.

A clear understanding of the exact channel of transmission mechanism of monetary policy is key towards an economic path of growth. So far, evidence on the effectiveness, dominance and strength of the different channels of transmission mechanism in Nigeria are mixed. According to Obafemi and Ifere (2015), this is evidenced in studies by " Jimoh (1990), Oke (1995), Uchendu (1994), Ojo (2000) Nnnana (2001), Adebiyi (2006), Ajayi (2007),CBN (2007;2008 and 2010), Adebiyi and Mordi (2009), Mbutor (2009),Oyaromade (2011),Nwosa and Saibu (2012)". Different methodologies such as VAR, VECMs and qualitative findings were adopted for these studies. However, only few studies from the US and other industrialized economies like Bernanke, Boivin and Eliasz (2005), Boivin, Kiley and Mishkin (2010) and Senbet (2008) have made a comparative study of FAVAR and VAR methodologies.

The choice of comparing the VAR and FAVAR approach in this study is inspired by the fact that even though VAR framework has become popular among economists over the past decade, they have remained controversial in the test of economic theories due to unstable and weak empirical results (Todd, 1990). Another possible challenge of the VAR based result is the non-inclusion of some significant variables in the investigation. When considering changes in contemporary history requiring short term time series, a solution that would need including more variables to the VAR turn out to be unpractical, (Boivin, Kiley\&Mishkin, 2010). Another shortcoming is that the VAR methodology only considers unexpected adjustments in monetary policy. According to Sims and Zha (1998), most policy changes are systematic. Given these short comings, and while retaining the flavour of the VAR, this study will be structured by 
enlarging its analysis by comparing the results with the new FAVAR method by Bernanke, Boivin and Eliasz (2005) which uses large information. The paper is further organized as follows: Section two makes a brief review of literature on monetary policy transmission mechanism in Nigeria while, FAVAR and VAR models are discussed in Section 3 as well as the conceptual framework. Section 4 attempts an analysis of the empirical results of VAR and FAVAR while, the study is finally concluded in section 5 .

\section{Review of Literature}

\subsection{Monetary Policy Transmission in Nigeria}

The transmission channels of monetary policy vary across countries. According to Obafemi and Ifere (2015), certain factors that may be responsible for this variations may include; "macroeconomic environment and structural economic conditions, the extent of development of capital markets, the health of and extent of development within the financial system as well as the major monetary policy instruments used by a country" According to Sanusi (2009), "an efficient and effective transmission mechanism of monetary policy can only be assured in an economically safe and sound environment characterized by a competitive banking system".

In Nigeria, the efficacy of monetary transmission mechanism is inhibited due to numerous factors, which the CBN has been trying to grapple with. These impediments are passing through the different channels of monetary transmissions like the interest, inflation, exchange rate and credit channels. Impediments arising from interest rates are due to the large and continuing increase that exists between deposit and lending rates. According to Sanusi (2009), this can be influenced by factors such as, prudential and reserve requirements, market structure, inflation, as well as non-interest expense credit risk and profit expectations of banks. Another impediment to monetary policy transmission is through the lending channel. This comes through bank loans which affects price of credit rather than quantity. In this case, monetary tightening decreases bank reserve and aggregate quantity of bank credits. This in turn leads to decrease in investment by bank-dependent borrowers and consumer spending. Other limiting factors of transmission mechanism can be through the balance sheet and asset channels. For the balance sheet channel, the failure of banks to adequately asses' credit occasioned by inadequate risk management know-how and shady accounting procedures are major impediments to transmission mechanism. While the impediments through assets prices operate through the underdeveloped state of the capital market. In Nigeria, the financial segment is occupied by banks, which account for a very large percentage of financial system assets, whereas the non-bank financial sub-sector such as the stock and mortgage market, insurance industry and the debt securities market are in their early years.

Monetary Policy in Nigeria is as old as the Central Bank of Nigeria. Although there have been a number of structural transformations in the conduct of monetary policy. The two major structural transformations are the Direct and indirect (market-based) approach. The direct approach (1974-1992) emphasizes direct monetary control. Under direct monetary policy, CBN relies on sectoral allocation and credit ceilings as monetary policy stance. According to Nnanna(2001), "during this period of direct control of Monetary Policy; monetary authorities directed financial resources at a compromise rates to sectors considered with right of precedence".

Indirect Monetary Policy (Market-based) approach was adopted to eliminate the twist and ineffectiveness in the financial system, triggered by the persistent usage of administrative controls with the objective of stimulating competition within the financial system (Ibeabuchi, 2007). The major instrument from 1993 is the Open Market Operation (OMO), later complimented by the reserve requirement, CBN securities and Moral suasion. The OMO involves the purchase or sale of eligible bills or securities by CBN in the open market with the aim of influencing deposit money bank's reserve balances, base money as well as the financial state of affair (Nnanna, 2007). However, despite the different monetary policy measures and transformational frameworks taken by CBN in recent times, the economy has failed to respond favorably and the exact channel of transmission mechanism of monetary policy has continued to be uncertain and unidentified, hence the need to explore the VAR and FAVAR approach.

\section{The Model}

\subsection{FAVAR}

In applying the specification for this study, the merit of including the variables in the system of equations will be adopted based on the peculiarities of the Nigerian economy by modifying the arrays of variables to suite the system. Therefore, one possible solution to the incomplete information in VAR model is including a small number of factors that effectively sum up the information contained in the numerous time -series variables. Adopting Senbet (2008), therefore;

Let $X_{t}$ be an ( $\left.\mathrm{N} \times 1\right)$ vector of informational time series stationary variables. 
Let $Y_{t} b e$ an $(M x 1)$ vector of observable stationary time series economic variables assumed to affect the changes in the economy. $\mathrm{Y}_{\mathrm{t}}$ is a subset of $\mathrm{X}_{\mathrm{t}}$, and this may include policy variables and other observable measures of prices and real activity. Often times, estimation using the VAR framework use only these observable measures summarized by about four to eight variables. One of the identified limitations of this approach is that $Y_{t}$ cannot incorporate the same information set as $\mathrm{X}_{\mathrm{t}}$.

According to Bernanke et al. (2005), assume a hand full of the information in Xt can be effectually abridged by a handful of unobserved $(\mathrm{K} \times 1)$ vectors of factors, Ft. "it is common place to think of the unobserved factors as capturing fluctuations in unobserved potential output or reflecting theoretically motivated concepts such as economic activity, price pressures, that cannot easily be represented by one or two series but rather reflected in a wide range of economic variables". According to Favero et al. (2005), the idea underlying the factor models is that "the economy is driven by a few common forces or factors and idiosyncratic errors". Studies by Stock and Watson (2005), and Favero et al. (2005), showed that "the vibrant factor model expresses Yt as a distributed lag of a small number of unobserved factors and idiosyncratic disturbances that are accepted to be serially correlated".

$$
\begin{gathered}
Y_{t}=\lambda(L) F_{t}+u_{t} \\
U_{t}=\delta(L) u_{t-1}+v_{t}
\end{gathered}
$$

Where

$\mathrm{F}_{\mathrm{t}}$ is a $(\mathrm{K} \times 1)$ vector of unobserved dynamic factors,

$\lambda(L)$ is an $(\mathrm{M} \times \mathrm{K})$ dynamic factor loadings and $v_{t}$ is said to be the white noise. Assume that the factors and disturbances are not correlated

Therefore equation (2),

$U_{t}=[I-\delta(L) L]^{-1} v_{t}$, and hence (1) becomes

$$
Y_{t}=\Lambda(L) F_{t}+\delta(L) Y_{t-1}+V_{t}
$$

Where

$\Lambda(L)=[I-\delta(L) L] \lambda(L)$ Define the evolution of factors as

$$
F_{t}=\Phi(L) F_{t}+\eta_{\mathrm{t}}
$$

Where

$\eta_{\mathrm{t}}$ is a $(\mathrm{K} \times 1)$ disturbance vector.

Substituting (4) into (3) and rearranging

$$
Y_{t}=\Lambda(L) \Phi(L) F_{t-1}+\delta(L) Y_{t-1}+\omega
$$

Where $\omega_{\mathrm{t}}=\Lambda(L) \eta_{\mathrm{t}}+\mathrm{v}_{\mathrm{t}}$

Combining equation (5) with the factor evolution equation (4) yields the FAVAR model:

$$
\left(\begin{array}{c}
\mathbf{F}_{\mathbf{t}} \\
\mathbf{Y}_{\mathbf{t}}
\end{array}\right)=\left(\begin{array}{cc}
\Phi(\mathrm{L}) & 0 \\
\Lambda(\mathrm{L}) \Phi(\mathrm{L}) \delta(\mathrm{L})
\end{array}\right)\left(\begin{array}{c} 
\\
\mathrm{F}_{\mathrm{t}-1} \\
\delta \mathrm{Y}_{\mathrm{t}-1}
\end{array}\right)+\left(\begin{array}{c}
\eta_{\mathrm{t}} \\
\omega_{\mathrm{t}}
\end{array}\right)
$$

Assuming the terms in $\Phi(\mathrm{L})$ is all zero then; the above system is reduced to the traditional VAR. If the true system is FAVAR, then the major defect of standard VAR framework is in the omitted variable bias. Furthermore, the above expression for FAVAR nests the VAR model (i.e., when $\Phi(\mathrm{L})=0$ ), this makes the two models easy to compare.

\subsection{Conceptual Framework}

The FAVAR framework is built on structural dynamic factor models first used by Bernanke, Boivin and Eliaz (2005). In their pioneering work, a standard VAR model was first augmented with factors to identify monetary policy shocks. The adoption of the FAVAR model was to solve the inherent problems identified in the VAR. another advantage of the FAVAR model is its ability to measure monetary policy effect using large macroeconomic data set. (Senbet, 2008)

The FAVAR method uses two-step estimation methods involving principal component analysis (Senbet, 2008). The first step is extracting the factors using PCA. The second step is incorporating the estimated factors into a VAR model 
as inputs. The FAVAR models employ factors instead of real variables. Each of these factors does not expect cointergration amongst itself and so is orthogonal.

In the case of standard VAR models, employing difference stationary variables involves cointegration among the non-stationary variables. This can serve as a proof to the relevance of vector error correction autoregression model. According to (Senbet 2008), the FAVAR techniques starts with "conducting principal component analysis using all the large informational time series data set (variables) represented by $(\mathrm{Nx} 1)$ vector of $\mathrm{V}_{\mathrm{t}}$ to get the first $\mathrm{K}+\mathrm{M}$ principal components denoted by $\mathrm{C}\left(\mathrm{F}_{t} \mathrm{Y}_{t}\right)$ " These estimated factors $\mathrm{F}_{t}$ are included in the space covered by $\mathrm{C}\left(\mathrm{F}_{t} \mathrm{Y}_{t}\right)$ which is not covered by $\mathrm{Y}_{\mathrm{t}}$, after which the dependence of $\mathrm{C}\left(\mathrm{F}_{\mathrm{t}} \mathrm{Y}_{\mathrm{t}}\right.$ on $\mathrm{y}_{\mathrm{t}}$ is removed by first, dividing the series in $\mathrm{Xt}$ into fast and slow- moving variables. The fast moving variables are those variables that react simultaneously to policy shocks or news (Senbet, 2008). While the slow moving variables are those that do not respond to monetary shocks simultaneously. The next step involves using PCA to obtain matrix of slow moving factors $\mathrm{C}\left(\mathrm{F}_{t}\right)$ and the regression.

$$
\mathrm{C}\left(\mathrm{F}_{\mathrm{t}} \mathrm{Y}_{\mathrm{t})}=\mathrm{B}^{\mathrm{f}} \mathrm{C}\left(\mathrm{F}_{\mathrm{t}}\right)=\mathrm{B}^{\mathrm{y}} \mathrm{Y}_{\mathrm{t}}+\mathrm{e}_{\mathrm{t}}\right.
$$

After extracting the factors, then VAR of $\mathrm{ft}$ and $\mathrm{Y}_{\mathrm{t}}$ is estimated. In this case the $\mathrm{Y}_{\mathrm{t}}$ covers the monetary policy instruments while rest of the variables such as inflation and output were handled as unobservable variables (Bernanke et al, 2005).

\subsection{Choice of Factors}

This study adopts the factors used earlier in the study by Obafemi and Ifere (2015) in analyzing monetary transmission in Nigeria using the FAVAR approach; borrowing from the novel idea of Belviso and Milani (2006) who partitioned the vector of economic variables $X_{t}$ to give them a clear meaning. The factors chosen for the study based on the factor loadings and correlation in each principal component are:

Financial market factor: This is used to test for efficiency and effectiveness of asset prices, stock prices, and dividend indexes.

Money factor: This explains money stock variables that can impact monetary policy e.g M1, M2, reserve money, deposits of money banks with CBN, currency in circulation, etc.

Inflation factor: This includes all of inflation variables in Nigeria such consumer and producer prices, fuel and food inflation, and others

Credit factor: this is an important factor that includes series loans and of private credit variables.

Interest rate factor: interest rate factor capture private and public bonds yield at different maturities.

Exchange rate factor: This is an intermediate policy variable that impact capital flow, external sector and value of domestic currency.

Real activity factors: This factor did not load highly in the principal component.

\section{Empirical Results}

To ascertain the exact importance and proportional contributions of given macroeconomic variables on policy variables, we adopt the impulse response function (IRF) and Variance decompositions. This brings out an exact picture of transmission shocks. With this, one can detect the degree and extent to which monetary policy actions affect the economy. The comparative importance of all random innovations is taken care of by the variance decomposition. It takes care of variables with short and long-term impacts on other variable of interest. This brings out a clear percentage of time series fluctuations attributed to other variables.

\subsection{VAR Result}

\section{(a). Impulse response function}

For VAR result, the estimated IRF of monetary policy rate to commercial and industrial loans for all commercial banks (CILCB) shows an initial gentle rise from below in reaction to the effect of interest rate shocks. This suggests that a monetary policy shock initially fosters a slight and gentle growth in CILCB before leveling out. The impulse response of inflation is slow but positive up to the tenth quarters. This shows a price puzzle in MPR and output.

The impulse response of the monetary policy rate (MPR) at the outset represents its positive shocks up to the first three quarters and levels out in at the tenth quarter. The nominal effective exchange rate (NEER) starts from the second quarter and initially rises up to the third quarter in reaction to monetary policy tightening, before taking zero levels at the sixth quarter. This suggests that monetary policy shocks present a slight and small increase in exchange rate before returning to normal levels.

The estimated impulse response of output due to monetary policy tightening shows an initial impact that starts from the first quarter (not when the policy was initiated). In this case, the output start rising sharply up to the third quarters and 
taking levels asymptotically without converging towards the benchmark zero-line. This suggests that a sudden monetary policy tightening will impact on output but gradually diverging from the benchmark level. For stocks traded (STT), the impulse response due to monetary policy tightening results in a small initial rise showing alternating signs and converging to the benchmark level towards the ninth quarter.

\section{b). Variance decomposition}

The result of the VAR specification shows that monetary policy shocks explained between 80 per cent and 95 per cent of the variance in CILCB. The percentage explained of INF ranged between 94 and 99 percent, while that of MRR ranged between 93 and 98 percent within the tenth period horizon.

The explanatory power (R-squared) of the VAR result is reasonably very high. The R-squared values range from 99.86 per cent for CILCB, 94.42 per cent for INF, 93.99 per cent for MPR, 97.48 per cent for NEER and 98.55 per cent for OUTPUT.

Response to Cholsesky One S.D. Innovations \pm 2 S.E.
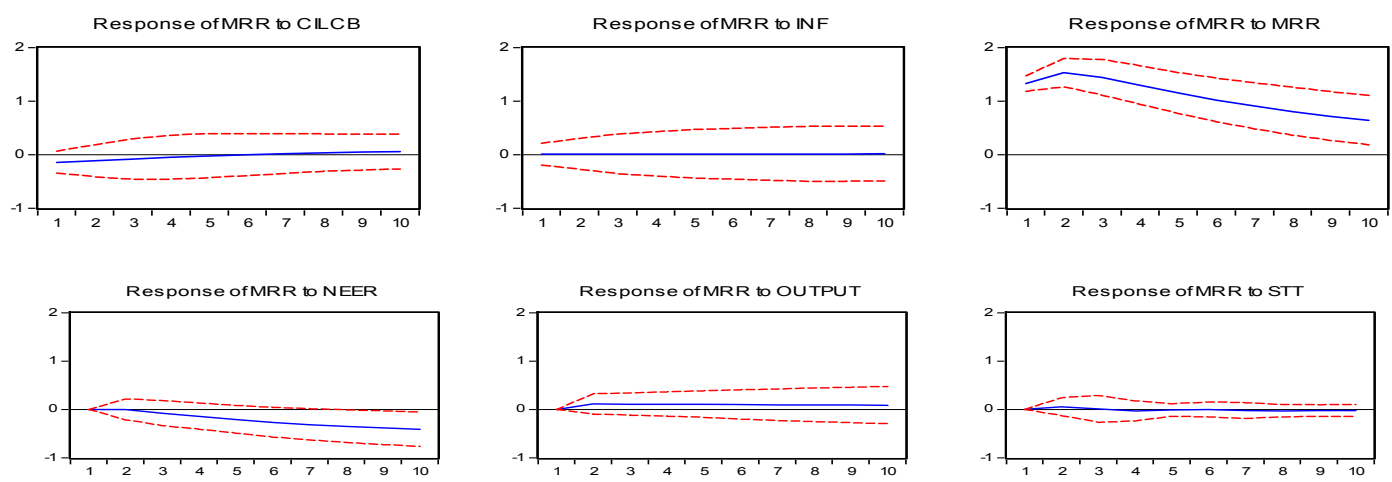

Figure 1. Impulse response function of VAR result

\subsection{FAVAR Result}

\section{Impulse response function of monetary aggregates}

The impulse response of aggregate macroeconomic money variables (Figure. 2) reflects its own gradual decrease presenting a falling pattern from the initial period. It levels out entirely after the fourth quarter within the benchmark zero line. The impulse response functions of monetary aggregates to interest rates, credit, exchange rate, inflation and stock market rates reveals a sharp and small negative fall from the zero baselines up to the third quarter before picking up gradually to terminate at the zero line. In terms of forecast error variance error decomposition, the result showed how variation in monetary aggregate accounted for by its own shock was highest varying from from 100 to 97.29 percent from first quarter to the tenth period.

Response to Cholsesky One S.D. Innovations \pm 2 S.E.
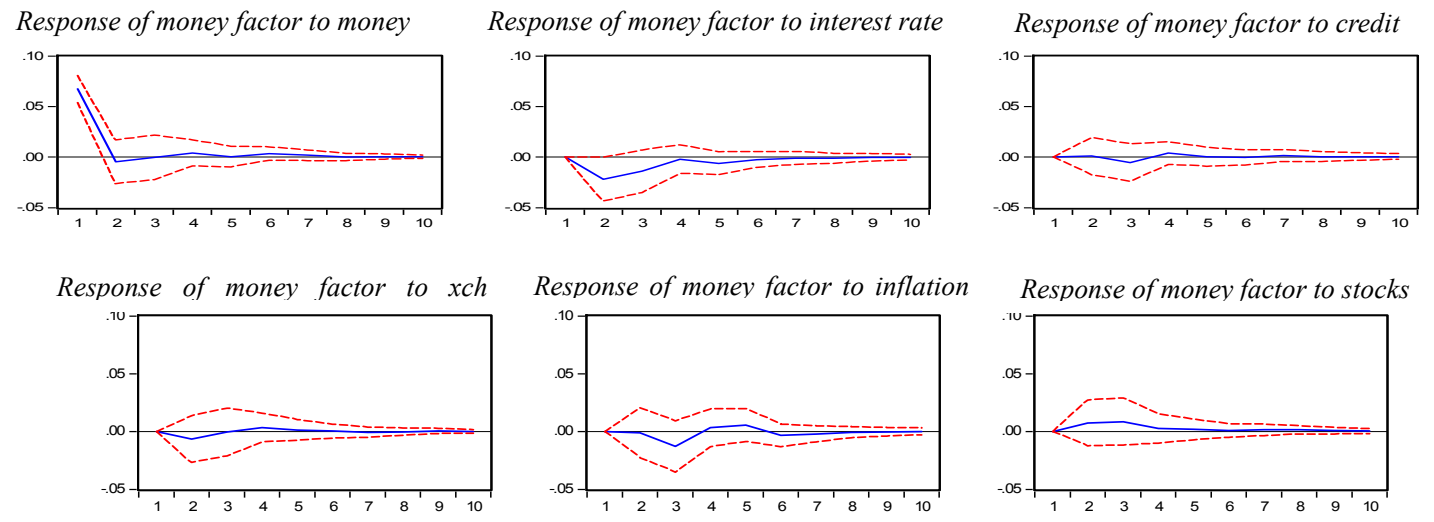

Figure 2. IRF of monetary aggregates 


\section{Interest rate channel (Impulse response function)}

Figure 3 presents the IRF of interest rate channel. Minimum rediscount rate (MRR) serves as the monetary policy shock variable. The IRF of interest rate to monetary aggregates shows that an unanticipated monetary shock causes a gentle fall of monetary aggregates that is positive in nature finally leveling out at zero in the fourth quarter. This is line with Ndekwu (2013) "that interest rate seems to have had weak impact on the real economy during the period 1981 to 2008" and Obafemi and Ifere (2015) result which asserts that "the impulse response of interest rates can be said to be consistent with a priori expectation. Interest rate replicates positive shock of its own and drops uninterruptedly from above the first five quarters. This shows a gentle falling pattern stagnating at the baseline i.e. zero benchmark by the seventh quarter. The observed gentle fall can be credited to the stifling consequence of contractionary monetary policy on the economy. According to them, "the estimated impulse response of interest rates to credit shows an initial rise (albeit with weak statistical significance) before leveling out at the benchmark after the third quarter". This shows that short term interest rate affect credit through some other factors such as exchange rate and stock market factors. This reveals that a rise in interest rate first attracts credit and slowly dampens it".

Based on findings from the study, there exists a negative response of exchange rate by monetary tightening in the short term, thereafter leveling out in the medium term. Apriori, "a rise in local interest rate will make deposits denominated in local currency to be further appealing and this result in local goods being more costly than foreign goods causing a drop in export after deductions and total output" Obafemi and Ifere (2015). The impulse response function of interest rate to inflation reveals a gyration of sharp negative fall up to the second quarter and a rise in the fourth quarter before leveling out to the benchmark level. This is in agreement with economic theory that interest rate affects inflation in the short run. "A given interest rate will produce much more monetary restraint when inflation is low and less volatile than when inflation is high". The lags in the transmission channels can be responsible for these gyrations "which are due to the time it takes for aggregate demand to respond to changes in interest rates and the time it takes for inflation to respond to output gaps" (Ajayi, 2007).

During a contractionary monetary shock, stocks respond negatively and slow to interest rate up to the sixth quarter A priori, when interest rates are low, stocks become more attractive means of raising household financial assets.

The variation in interest rate accounted for by monetary aggregates is low and varies from 4.8 percent in the first quarter thereafter leveling out at 8.3 percent, 8.7 percent from the third to the tenth quarters respectively.

Response to Cholsesky One S.D. Innovations \pm 2 S.E.
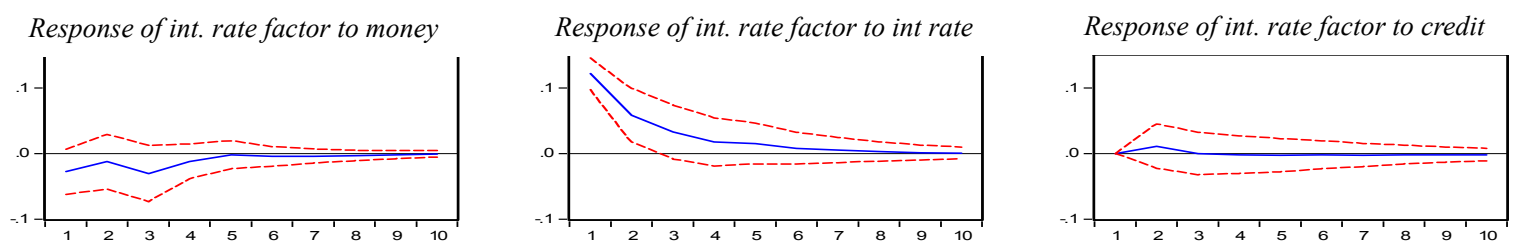

Response of int. rate factor to Exch rate

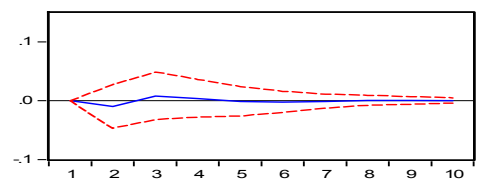

Response of int. rate factor to inflation

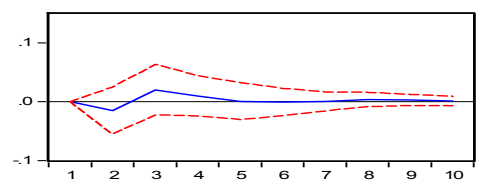

Response of int. rate factor to Stock

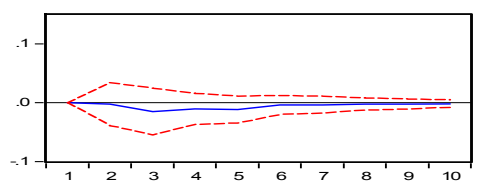

Figure 3. IRF of interest rate channel

\section{Credit channel (Impulse response function)}

In Figure 4, IRF of credit to monetary aggregates present that a one SD shock to monetary aggregates brings about a swift rise in credit from below the zero benchmark to a highest peak after immediately above the fourth quarter. That a tight monetary shock shows that a one SD shock to interest rate present a fast fall in credit at levels. This fall is experienced within the medium and long- term. Monetary shock on credit channel reflects its own positive shock. 
The IRF of credit and inflation showed a negative decline from zero benchmark level up to fourth quarters before leveling out from the sixth quarter. This shows that credit affect inflation and exchange rate in the economy negatively. This result is in line with results obtained by Ndekwu (2013) "that credit channel in the financial sector provides a linchpin in the process by which monetary policy impact the economy in Nigeria between 1981 to 2008".

The forecast error variance decomposition result of the credit factor shows that credit factor variation accounted for by its own shock is the highest and varies from 84.79 percent in the first quarter to 54 percent from the fourth quarter up to the tenth quarter. The variations of credit in response to other monetary transmission channels are low.

Response to Cholsesky One S.D. Innovations \pm 2 S.E.
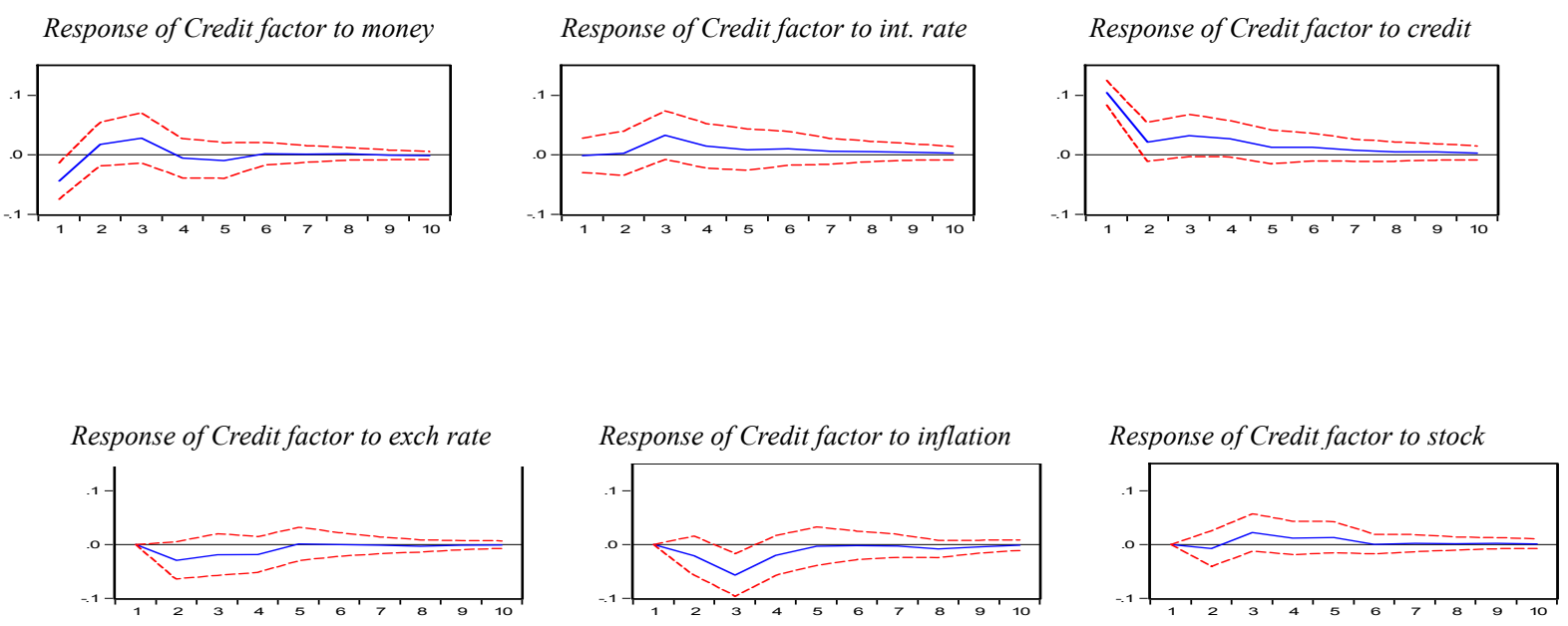

Figure 4. IRF of credit channel

\section{Impulse response function of exchange rate channel}

Real effective Exchange Rate (REER) served as the monetary policy shock variable for Exchange Rate channel. In Figure 5, a one SD shock to monetary factor causes a swift increase in exchange rate reaching a maximum at the fourth quarter before making a quick return within the fifth quarter before leveling out in the seventh quarter. The impulse response of exchange rate to inflation shows that a one standard deviation shock to interest rate results in a positive but slow movement of exchange rate up to the fifth quarter before touching the zero bench mark.

Exchange rate variation to inflation, credit, and stock channel factors are low ranging from four to to seven, eight to eleven, and one to two respectively. 
Response to Cholsesky One S.D. Innovations \pm 2 S.E.

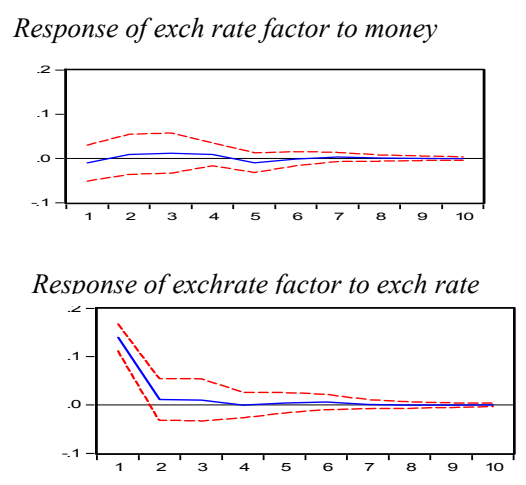

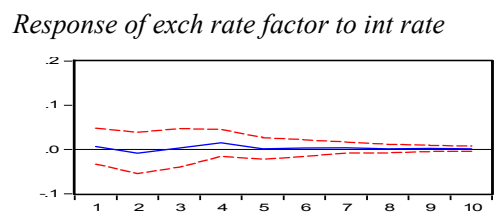

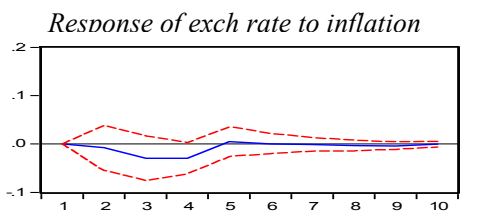

Response of exch rate factor to credit factor

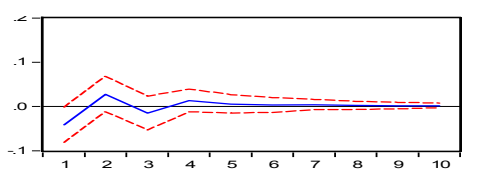

Response of exch rate to stock $m k t$

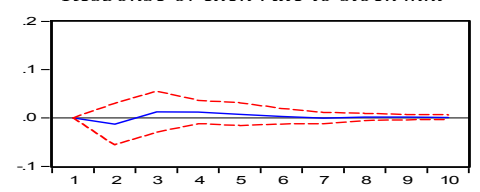

Figure 5. IRF of Exchange rate channel

\section{Impulse response function of inflation channel}

In the wake of a monetary policy tightening, the impulse response of inflation to monetary aggregates (Figure 6), initially rises slightly above the benchmark level after the second quarter and then gradually declines, leveling out from the third over the medium to the long-term. A monetary contraction reveals impulse response of inflation to interest rate below the zero benchmark level from the first quarter to the tenth quarter. This is in line with economic theory that high inflation and prices influence interest rates or cost of capital in an economy.

The impulse response function of inflation to both credit and exchange rate reported in levels, both falls below the benchmark level from the short to medium term. For credit, there exist a sharp fall and indeed below the zero benchmark level up to the fourth quarter following a tight monetary policy before leveling out. While that of exchange rate leveled out from the first quarter to the tenth quarter. This is an indication that monetary policy tightening affects credit more sharply than exchange rate.

The IRF of inflation shows that an unexpected contractionary monetary shock causes a sharp fall in prices, to the highest level after the fourth quarter. This is agrees with apriori expectation that a contractionary monetary policy reduces prices.

From the variance decomposition result, the forecast error variance decomposition, of inflation channel on money aggregates (Figure 5), showed that the variation in inflation rate accounted for by monetary aggregates is low and levels out from the first to tenth period at 6.1 to 6.5 per cent respectively.

Response to Cholsesky One S.D. Innovations \pm 2 S.E.

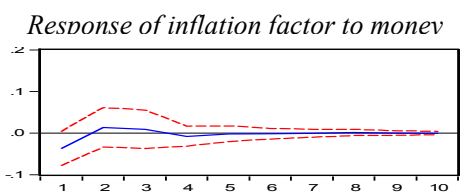

Response of inflation factor to exch rate

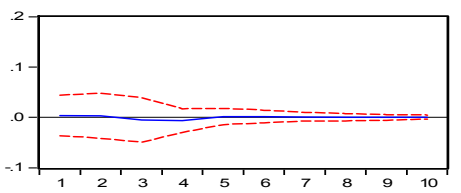

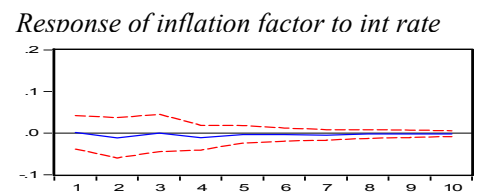

Response of inflation factor to inflation

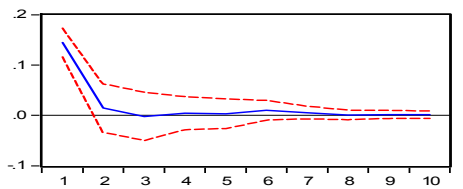

Response of inflation factor to credit

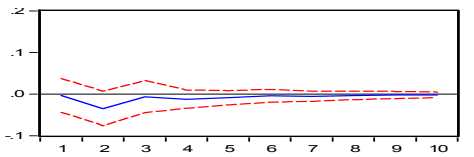

Response of inflation factor to stock

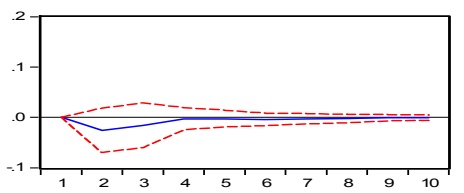

Figure 6. IRF of inflation channel 


\section{Stock market channel (Impulse response function)}

Figure 7 displays the impulse responses of Stocks and interest rate. A monetary policy tightening implemented through monetary aggregates such as credits and exchange rate, results in a slow movement of stocks above levels up to the third quarter and then starts declining up to the sixth quarter before reaching the zero bench mark. For inflation, the trend is swift and sharper, as a one standard deviation shock to inflation generates sharp gyrations in stock prices factor, reaching the highest point in quarter three with a swift fall up to quarter five before leveling out from below the sixth quarter.

For stocks, a one standard deviation shock resulting from monetary tightening reflects a sharp and negative shock up to the zero benchmark in the second quarter. The percent forecast error variance of stock market factor due to its own shock seems to be the largest among the six monetary policy transmission channels under discussion. The monetary shock on stock channel explains over half of the variance of the tenth horizon. This variation is within the range of 98.09 percent to 80.68 percent within the first to tenth period horizon respectively.

\section{Response to Cholsesky One S.D. Innovations \pm 2 S.E.}

Response of Stock to money factor

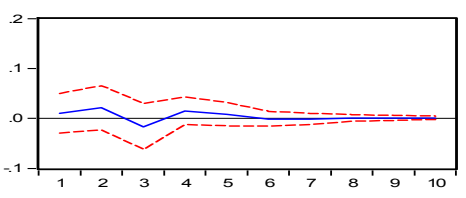

Response of Stock to stock mkt

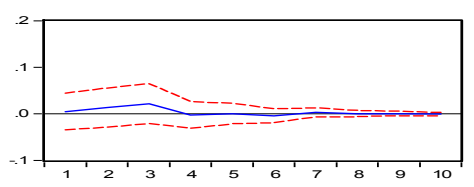

Response of Stock to interest rate

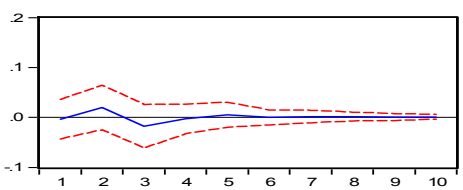

Response of Stock to credit factor

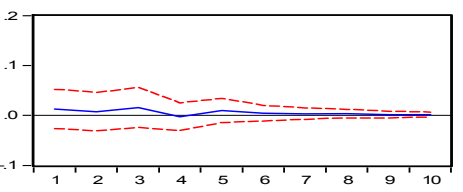

Response of Stock to Stock
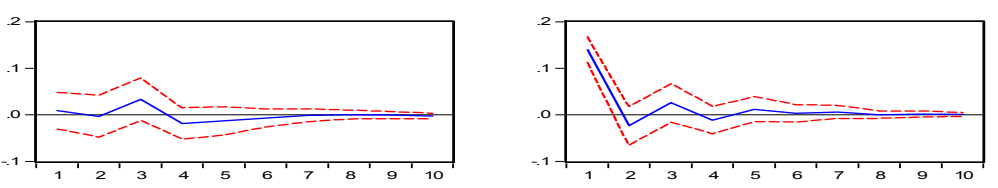

Figure 7. IRF of stock market channel

\subsection{VAR - FAVAR Comparison}

To evaluate the empirical plausibility of informational input of the factors is to make a comparison of the FAVAR and VAR results. In comparing the VAR results with the FAVAR, six variables were estimated in the model. The response of some variables such as output, MRR, CILCB shows an initial rise as a result of a contractionary monetary policy which is an indication of price puzzle. This is a common characteristic of the VAR model.

However, although the result was similar for exchange and inflation rates in terms of duration, the impact of contractionary shocks was more persistent in the FAVAR than in the VAR except for interest rates (MRR) in the VAR which peaked in the third quarter before declining asymptotically towards the benchmark zero level. This is however, in contrast to the result obtained by DeCarvalho and Rossi (2009).

In the VAR model, the responses indicated were not very significant and precise. This further buttresses the fact that the reduced number of observations can contribute to results not being precise. In summary, the value of the R-squared of the FAVAR model suggests that just a negligible fraction of the variables are explained in the FAVAR model, hence the low explanatory power in almost all the factors except for credit factor with a sizeable explanatory power of 48.6 per cent. The explanatory power of the other factors are 21.7 per cent for the monetary aggregate factor, 33.8 per cent for the interest rate factor,18.4 per cent for the exchange rate factor , 14.3 per cent for the inflation factor and 23.7 per cent for the stock factor. For the VAR model the explanatory power is very high. Therefore, since the R-squared for the FAVAR result is low, it can be deduced that adding more variables in the FAVAR analysis as against the 53 originally used for this study may give more meaningful results. 


\section{Conclusion}

This empirical study tests the strongest and most dominant monetary transmission channels in Nigeria. It compared the result of the FAVAR with the traditional VAR framework for a better and clearer analysis of the transmission mechanism. It employed quarterly data from 1970 to 2013. The FAVAR used 53 macroeconomic variables and PCA was used to estimate the factors.

With the impulse responses result, we compared the empirical plausibility of FAVAR model with the benchmark traditional VAR approach. We examined the transmission of shocks with small number of macro variables which often present the risk of ignoring the actual degree of the impact of shocks to the economy.

To test for dominance and strength of transmission channels as hypothesized, the FAVAR model was estimated. Results obtained from impulse response and variance decomposition present interest rates and credit channels as the most strongest and dominant transmission channels. Next in the order is the money channel M2, although with a negligible impact.

Specifically, our findings show, interest rates and credit channels to be the most strongest and dominant channel of monetary shocks. Although, exchange rate and money channel were significant, they were not as pronounced as interest and credit channels. A small increase in exchange rate shocks only impacts little on macroeconomic variables. No significant impact was found for stock channel showing an insignificant role in the monetary transmission process. Stocks channel levels out within the first two quarters during transmission process.

A comparative analysis of the VAR and FAVAR results on monetary dynamics in Nigeria are the core interest of this study. The FAVAR result confirms earlier findings by Obafemi and Ifere (2015) which conclude that "a tight monetary policy shock triggers monetary growth before putting forth a dampening influence on the economy, leveling out at the zero bench mark in the medium to long term. This way, the Central Bank of Nigeria uses the interest rate and credit channels as policy variables to impact the economy". While both models allow for the generation of impulse response functions, the FAVAR model provides a more comprehensive picture of the channels of transmission of monetary policy in Nigeria.

Findings conclude that, although both methods appear to generate qualitatively related results, but the FAVAR model is more plausible with large data set. The traditional VAR result though plausible, still exhibits the prize puzzle problem. For example, a tight monetary policy shock causes a raise rather than a decline in prices. The results of the study are consistent with theoretical expectations and results obtained in known similar studies such as De Carvelho \& Rossi, (2009).

\section{Policy Recommendation}

Based on findings from the study, it is recommended that interest rate and credit channels should be improved upon by $\mathrm{CBN}$ as policy variables in the conduct of monetary policy; since they have been identified as the most effective and dominant channels of monetary transmission. Next in the order is exchange rate channel. The policy approach to achieve this can be that of stimulating and emphasizing judicious management of these identified channels (interest, credit and exchange rate channels). It is through this policy approach, that growth can be stimulated in distinct economic sectors. According to Obafemi and Ifere (2015) "to stimulate output for development through credit channel of transmission, government and monetary policy makers should strengthen the Nigeria judicial system and improve on financial regulatory reforms. These reforms can come through tightening of credit worthiness standards of potential borrowers. This will cut down the amount of non-performing loans and enhance quality of credit, which in turn will strengthen the credit channel of transmission mechanism. Also more legal backing should be given to the Nigeria Deposit Insurance Corporation (NDIC) and other regulatory agencies of the CBN. This can be achieved through the enforcement of regulations requiring commercial banks to strengthen their accounting standards, corporate governance as well as improve and strengthen creditors' rights and capabilities of banks to assess credit applications and enforce collateral".

\section{References}

Adebiyi, M. A., \& Mordi, C. N. O. (2009). Monetary policy transmission mechanism inestimated dynamic stochastic general equilibrium (DGSE) for the Nigerian economy. CBN Economic and Financial Review.

Ajayi, M. (2007). Monetary policy transmission mechanism in Nigeria. Central Bank of Nigeria Economic and Financial Review, 45(4), 91-107.

Belviso, F., \&Milani, F. (2006). Structural factor-augmented VARs (SFAVAR) and the effects of monetary policy. Topics in Macroeconomics, 6(3), 1-46. 
Bernanke, B. Boivin, \& Eliasz, P. (2005). Measuring the effects of monetary policy: Afactor-augmented vector autoregressive (FAVAR) approach. The Quarterly Journal of Economics, 120(1), 387-422.

Bernanke, B. S., \& Blinder, A. S. (1988). Credit money and aggregate demand. American Economic Review papers and Proceedings, 78, 435-439.

Bernanke, B. S., \& Gertler, M. (1995). Inside the black box: The credit channel of monetary policy transmission. Journal of Economic Perspective, 9(4), 27-48.

Boivin, J., Kiley, M. T., \&Mishkin, F. (2010). How has the monetary transmission mechanism evolved over time? NBER Working Papers, (15879), National Bureau of Economic Research, Inc.

Central Bank of Nigeria. (2010). Monetary policy review. Maiden Edition. CBN Half Year Economic Report for 2010. Retrieved from http://www.cbn.gov.ng

de Carvalho, M. D., \& Rossi J. L.jnr. (2009). Identification of monetary policy shocks and their effects: FAVAR methodology for the Brazilian economy. Brazilian Review of Econometrics, 29(2), 285-313.

Ibeabuchi, O. (2007). Overview of monetary policy in Nigeria. Central Bank of Nigeria Economic and Financial Review.

Mbutor, M. O. (2009). The dominant channels of monetary policy transmission in Nigeria: An empirical investigation. CBN Economic and Financial review, 47(1).

Mishkin, F. S. (2007). Housing and monetary transmission mechanism. Staff Working Papers in the Finance and Economic Discussion Series (FEDS) Jackson Hole Symposium, Jackson Hole, Wyoming.

Ndekwu, E. C. (2013). An analysis of the monetary policy transmission mechanism and the real economy in Nigeria. Central Bank of Nigeria occasional papers No. 43.

Nnanna, O. J. (2001). Monetary policy framework in Africa: The Nigerian experience. Discussion paper, South African Reserve Bank Conference.

Nwosa, P. I., \& Saibu, M. O. (2012). The monetary transmission mechanism in Nigeria: A sectoral output analysis. International Journal of Economics and Finance. http://dx.doi.org/10.5539/ijef.v4n1p204

Obafemi, F. N., \& Ifere, E. O. (2015). Monetary policy transmission mechanism in Nigeria: A FAVAR approach. International Journal of Economics and Finance, 7(8). http://dx.doi.org/10.5539/ijef.v7n8p229

Oke, B. A. (1995). The conduct of monetary policy by the central bank of Nigeria (1959-1995). CBN Economic and Financial Review, 33(4).

Oyaromade, R. (2010). Monetary policy transmission mechanism in Nigeria: A VECM Approach. Nigeria Journal of Economic and Social Studies (NES) Journal, 44(2), 231-251.

Sanusi, L. A. S. (2009). Assessment of current development in the Nigerian economy and the CBN policy action. BIS Review, 89.

Senbet, D. (2008). Measuring the impact and international transmission of monetary policy: A factor augmented vector autoregressive (FAVAR) approach. European Journal of Economics, Finance and Administrative Studies, (13).

Sims, C. A. (1992). Interpreting the time series facts: The effects of monetary policy and financial repression and economic growth. European Economic Review, 36(5).

Taylor, J. B. (1995). The monetary transmission mechanism: An empirical framework. Journal of Economic Perspectives, 9(4), 11-26.

Theil, H. (1971). Principles of Econometrics. John Wiley, 46-55.

Uchendu, O. A. (1996). The transmission of monetary policy in Nigeria. Economic and Financial Review, Central Bank of Nigeria, 34(2), 606-625. 